\title{
Scales Used to Assess Stress Level and Mental Health During the Covid 19 Pandemic: Systematic Review
}

\author{
Ednaldo Dos Santos ${ }^{1 *}$, Chen Chia Ling ${ }^{2}$ and Adina Hiller ${ }^{3}$ \\ ${ }^{1}$ Doctoral Program in Promotion of Autonomy and Social Healthcare in the Unit, University of Valencia, Spain \\ ${ }^{2}$ National Chi Nan University, Taiwan \\ ${ }^{3}$ University in Konstanz, Germany
}

*Corresponding author: Ednaldo Dos Santos, Doctoral Program in Promotion of Autonomy and Social Healthcare in the Unit, University of Valencia, Av. Blasco Ibanez 21. 46010, Valencia, Spain

\begin{tabular}{|c|c|}
\hline ARTICLE INFO & ABSTRACT \\
\hline Received: 彗 March 24, 2021 & $\begin{array}{l}\text { This systematic review aims to identify the scales used in studies related to the } \\
\text { impact of COVID } 19 \text { on the increase in mental disorders. Initially, } 265 \text { studies that met }\end{array}$ \\
\hline Published: March 31, 2021 & the review criteria were included. The use of 411 different scales was identified. It was \\
\hline
\end{tabular}

A. Scales Used to Assess Stress Level and Mental Health During the Covid 19 Pandemic: Systematic Review. Biomed J Sci \& Tech Res 34(5)-2021. BJSTR. MS.ID.005624.

Keywords: COVID 19; Mental Disorders; Stress; Mental Health

\section{Introduction}

\section{COVID-19}

At the end of December 2019, the world became aware of the existence of a new virus that was in the city of Wuhan (China), but in a few months, this virus spread in practically all countries on the planet, becoming a global pandemic [1]. In addition to the problems related to the physical health of those who contracted the virus, COVID 19 has become a major cause of problems in the psychological health and well-being of the world population [2]. Recent studies, such as [2], show an exponential increase in people with high stress symptoms, others like Elbay et al. and Ballou et al. showing a significant increase in the number of cases of people with depression and anxiety [3-5]. One of the main causes of illness in the mental health of the world population is stress [6]. And it was proven that in the lockdown period, there was a significant increase in the population's stress levels, due to concerns about the economy, access to inadequate information, lack of personal space in the house, boredom, little social life, care not to contracting the virus, anxiety about the appearance of the vaccine and the loss of relatives and friends [7].
Considering the countless psychological problems that COVID 19 caused in the population, researchers from several countries are dedicated to identifying these cases of psychological aging in the population $[8,9]$. However, in order to obtain a parameter with less stringency, it is important to use validated instruments that are translated into different languages, so that it is possible to have a more uniform global data, as well as the creation of specific instruments for assessing mental health caused by COVID 19, as a mention (Ballou \& Palsson). In order to identify the most used methods for assessing stress related to COVID 19, a systematic review was carried out in the main scientific databases, enabling other researchers to identify which scale is most often used and replicate in their studies.

General Objective: Provide an updated parameter regarding the scales that are used in different countries to identify the levels of stress, depression and anxiety caused by COVID 19.

Methods Protocol: For the development of the systematic review, we followed the indications of the PRISMA guide, which 
appoints the following steps: define your purpose, formulate the question, search for literature, evaluate the data, analyze the data and present the results [10-13].

Records: The included and e x c l u d e d study data is available at https://docs.google. com/spreadsheets/d/1uGFdVoY3uMISdb4iI35ZCMQVeYCqL3JA s5nVdJNn0w

\section{Eligibility Criteria}

Selection Criteria: As a criterion for research, studies that address COVID 19 and have the relationship with stress, which have quantitative data, were chosen.

\section{Inclusion Criteria}

a) Research written in the Spanish, English or Portuguese

b) Studies carried out between the period of January 1, 2020 to December 31, 2020

c) Full text studies available

d) Studies that have used any stress assessment tool

e) Studies that present statistical data regarding stress levels

f) Studies that present data related to depression and anxiety.

\section{Exclusion Criteria}
a) Systematic and literature reviews
b) Theoretical studies
c) Stress in health professionals
d) Research that reports stress in other professionals
e) Stress in people who have a disease

\section{Information Sources}

To search the data, the following databases were used: Cochrane Central Register of Controlled Trials, in the MEDLINE database (Latin American and Caribbean Literature in Health Sciences), LILACS (Virtual Health Library), SCIELO (Scientific Electronic Library Online) and PsycINFO.

\section{Searches}

For the searches, the following terms will be used as limited vocabulary and thesauri: "COVID 19", "stress", in the Spanish, Portuguese and English languages, with the following combinations (Figure 1).
In Spanish:

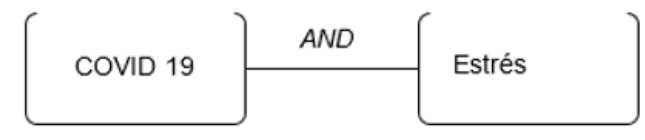

In English

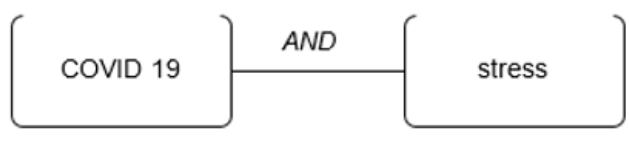

In Portuguese

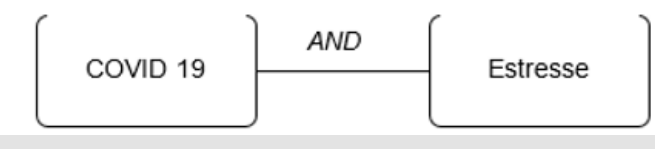

Figure 1.

\section{Selection of Studies}

In order to identify and gather the largest number of relevant works, in the first step, all the publications that contained the keywords in the title, abstract and text were included in the search engines. The second step was the reading and analysis in the integral of the texts that contemplated one of the inclusion criteria.

\section{Data Collection Process Types of Study Methods}

Among the various classifications of study methods, those that meet the requirements of this research are experimental, observational, cross-sectional and longitudinal studies, which belong to studies with a unit of analysis or in a group of individuals.

\section{Data Evaluation}

In this evaluation, the identified articles were reviewed, classifying them according to the title and abstract, selecting those that met the inclusion criteria and discarding them if it could not be verified that they did not meet them.

\section{Checking Protocol}

A protocol was developed whose purpose is to detail the requirements for the selection of articles and to allow the information to be displayed, so that other reviewers can detect ambiguity or application problems. The check protocol is available at https://docs.google.com/spreadsheets/d/1uGFdVoY3uMISdb4i I35ZCMQVeYCqL3JAs5nVdJNn0w/edit\#gid=0

\section{Literature Search}

All online publications of journals, university theses and abstract were included, between the period of February 1, 2020 
to December 20, 2020. For the searches, the following terms were used as limited vocabulary and thesauri: "COVID 19", "stress", in the Spanish, Portuguese and English languages. The results in the databases (Table 1). The sum of the results presented was 4272 studies, but most were discarded because they did not meet any of the criteria of this investigation. Of these 4272 studies, 319 articles were selected for full reading, as they met at least 1 of the inclusion criteria. Of these, 8 were duplicates and 46 were excluded because they did not meet all the review criteria, thus subtracting 265 that will be used in this study (Table 2).

Table 1.

\begin{tabular}{|c|c|c|c|}
\hline Date base & Estrés & Stress & Estresse \\
\hline Cochrane & 1 & 1 & 1 \\
\hline MEDLINE & 9 & 3160 & 1 \\
\hline Scielo & 71 & 48 & 34 \\
\hline PsycInfo & 9 & 618 & 319 \\
\hline
\end{tabular}

Table 2.

\begin{tabular}{|c|c|}
\hline Scale Name & $\begin{array}{c}\text { Number of studies } \\
\text { you used }\end{array}$ \\
\hline General Anxiety Disorder-7 scale (GAD-7) & 52 \\
\hline Depression, Anxiety and Stress Scales (DASS-21) & 48 \\
\hline Patient Health Questionnaire (PHQ-9) & 48 \\
\hline Perceived Stress Scale (PSS 10) & 48 \\
\hline Posttraumatic stress disorder symptoms & 20 \\
\hline Impact of Event Scale-Revised (IES-R) & 16 \\
\hline Poor psychological well-being & 12 \\
\hline COVID Stress Scales (CSS) & 10 \\
\hline Patient Health Questionnaire (PHQ-2) & 9 \\
\hline Connor-Davidson Resilience Scale (CD-RISC-10) & 8 \\
\hline COVID-19-Related Stress & 8 \\
\hline Fear of COVID-19 Scale (FCV-19S) & 8 \\
\hline Insomnia Severity Index (ISI) & 7 \\
\hline Patient Health Questionnaire (PHQ-4) & 7 \\
\hline Beck Depression Inventory (BDI) & 6 \\
\hline Impact of Event Scale (IES) & 6 \\
\hline Scale of Perceived Social Support (MSPSS) & 6 \\
\hline Templer Death Anxiety Scale (TDAS) & 6 \\
\hline Use of Technology for Child Education & 6 \\
\hline Beck Anxiety Inventory (BAI) & 5 \\
\hline Brief Symptom Inventory (BSI) & 5 \\
\hline General Anxiety Disorder (GAD-2) & 5 \\
\hline Hospital Anxiety and Depression Scale (HADS) & 5 \\
\hline Parental Stress Scale (PSS) & 5 \\
\hline $\begin{array}{l}\text { Peritraumatic stress symptoms related to } \\
\text { COVID-19 }\end{array}$ & 5 \\
\hline State-anxiety (S-Anxiety) & 5 \\
\hline Acute Stress Disorder (ASD) & 4 \\
\hline Alcohol Use Disorders Identification Test (AUDIT) & 4 \\
\hline
\end{tabular}

\begin{tabular}{|c|c|}
\hline Perceived Stress Scale (PSS-4) & 4 \\
\hline Self-Rating Depression Scale (SDS) & 4 \\
\hline $\begin{array}{l}\text { WHO Quality of Life Instrument-Short Form } \\
\text { (WHOQOLBREF) }\end{array}$ & 4 \\
\hline Athens Insomnia Scale (AIS) & 3 \\
\hline Big Five Inventory (BFI) & 3 \\
\hline $\begin{array}{l}\text { Center for Epidemiologic Studies Depression Scale } \\
\text { (CESD-R) }\end{array}$ & 3 \\
\hline COVID-19 Related anxiety & 3 \\
\hline Event Scale-Revised (IES-R) & 3 \\
\hline Obsessive-Compulsive Inventory-Revised (OCIR) & 3 \\
\hline Patient Health Questionnaire (PHQ-15) & 3 \\
\hline Positive perception of interventions & 3 \\
\hline Post-Traumatic Stress Disorder (PTSD) & 3 \\
\hline Symptom Checklist (SCL-90) & 3 \\
\hline Adolescent student's alienation scale (ASAS) & 2 \\
\hline $\begin{array}{l}\text { Brief Coping Orientation to Problems Experienced } \\
\text { (COPE) }\end{array}$ & 2 \\
\hline Brief Illness Perception Questionnaire (BIPQ) & 2 \\
\hline Brief Resilience Scale (BRS) & 2 \\
\hline Brief Resilient Coping Scale (BRCS) & 2 \\
\hline Buss-Perry Aggressive Questionnaire (BPAQ) & 2 \\
\hline Cognitive social capital scale (CSCS) & 2 \\
\hline Coronavirus Anxiety Scale (CAS) & 2 \\
\hline Escala de Estresse Percebido (EEP-10) & 2 \\
\hline Escala de ideation suicide de Beck (SSI) & 2 \\
\hline $\begin{array}{l}\text { Five Facets Mindfulness Questionnaire Short Form } \\
\qquad \text { (FFMQ-SF) }\end{array}$ & 2 \\
\hline General health questionnaire (GHQ-12) & 2 \\
\hline Global Severity Index (GSI) & 2 \\
\hline International Trauma Questionnaire (ITQ) & 2 \\
\hline Intolerance of Uncertainty Scale (IUS-12) & 2 \\
\hline Kessler Psychological Distress Scale (K6) & 2 \\
\hline Loneliness Scale & 2 \\
\hline Mental Health Lifestyle Scale (MHLSS) & 2 \\
\hline $\begin{array}{l}\text { Multidimensional Survey of Perceived Social } \\
\text { Support (MSPSS) }\end{array}$ & 2 \\
\hline Negative emotions questionnaire & 2 \\
\hline Openness scale & 2 \\
\hline Pandemic-related stress factors (PRSF) & 2 \\
\hline Patient Health Questionnaire (PHQ-8) & 2 \\
\hline $\begin{array}{l}\text { Patient-Reported Outcomes Measurement } \\
\text { Information System (PROMIS) }\end{array}$ & 2 \\
\hline Perceived Stress Related to COVID-19 & 2 \\
\hline Perceived Stress Scale for COVID (PSS-C) & 2 \\
\hline $\begin{array}{c}\text { Perception of COVID Impact on Student Well- } \\
\text { Being }(\mathrm{CI})\end{array}$ & 2 \\
\hline $\begin{array}{l}\text { Psychological Distress instrument Kessler-10 } \\
\text { (K10) }\end{array}$ & 2 \\
\hline Quality of Marriage Index (QMI) & 2 \\
\hline
\end{tabular}




\begin{tabular}{|c|c|}
\hline Ryff Measures of Psychological Well-being & 2 \\
\hline Scale of Perceived Stress Related & 2 \\
\hline Negative emotions questionnaire & 2 \\
\hline Openness scale & 2 \\
\hline Pandemic-related stress factors (PRSF) & 2 \\
\hline Patient Health Questionnaire (PHQ-8) & 2 \\
\hline $\begin{array}{c}\text { Patient-Reported Outcomes Measurement } \\
\text { Information System (PROMIS) }\end{array}$ & 2 \\
\hline Perceived Stress Related to COVID-19 & 2 \\
\hline Perceived Stress Scale for COVID (PSS-C) & 2 \\
\hline $\begin{array}{c}\text { Perception of COVID Impact on Student Well- } \\
\text { Being (CI) }\end{array}$ & 2 \\
\hline $\begin{array}{c}\text { Psychological Distress instrument Kessler-10 } \\
\text { (K10) }\end{array}$ & 2 \\
\hline Quality of Marriage Index (QMI) & 2 \\
\hline Ryff Measures of Psychological Well-being & 2 \\
\hline Scale of Perceived Stress Related & 2 \\
\hline
\end{tabular}

\section{Results}

As a result, two 265 studies have been analyzed, for which 411 different scales were identified, which were used to measure the level of stress, depression, anxiety, satisfaction with life, wellbeing, social conviviality among other aspects, which were applied in 38 countries. Below follows a list of the scales that were used in more than 1 study.

\section{Discussion}

From this analysis, we noticed that only $20 \%$ of the studies use the same scales to measure the level of stress, depression and anxiety of the participants. What makes it difficult to carry out meta-analysis and thus have a more precise parameter of the situation of mental disorders in the world. Another problem found in this review is the little use of scales that were created specifically to measure mental health related to COVID 19, considering that the most used scales were not designed to analyze mental health in a pandemic period. We hope that the present study will contribute to standardize the new studies and thus enable a more detailed analysis related to this theme.

\section{References}

1. Elbay RY, Kurtulmuş A, Arpacioğlu S, Karadere E (2020) Depression, anxiety, stress levels of physicians and associated factors in Covid-19 pandemics. Psychiatry research 290: 113130.

2. Shah S, Mohammad D, Qureshi M, Abbas MZ, Aleem S (2020) Prevalence, Psychological Responses and Associated Correlates of Depression, Anxiety and Stress in a Global Population, During the Coronavirus Disease (COVID-19) Pandemic. Community mental health journal 27: $1-10$.

3. Sherman A Lee (2020) Coronavirus Anxiety Scale: A brief mental health screener for COVID-19 related anxiety. Death Studies 44(7): 393-401.

4. (2020) World Health Organization. Novel coronavirus-China: Disease outbreak news: WHO; 2020 https://www.who.int/csr/don/12january-2020-novel-coronavirus-china/en/

5. Ballou S, Gray S, Palsson OS (2020) Validation of the Pandemic Emotional Impact Scale. Brain, behavior, \& immunity health 9: 100161.

6. Dos Santos EA, Marchant Sánchez E, Niguez Ortiz MÁ, Oliver Germes A (2019) Effects of music therapy in depression and anxiety disorder. Life Research 2(2): 64-70.

7. Cisler JM, Koster EH (2010) Mechanisms of attentional biases towards threat in anxiety disorders: An integrative review. Clinical psychology review 30(2): 203-216.

8. Brooks SK, Webster RK, Smith LE, Woodland L, Wessely S, et al. (2020) The psychological impact of quarantine and how to reduce it: rapid review of the evidence. Lancet 395(10227): 912-920.

9. Ballou S, Gray S, Palsson OS (2020) Validação da Escala de Impacto Emocional Pandêmico. Cérebro, comportamento e imunidade - saúde 9: 100161.

10. Stanton R, To QG, Khalesi S, Williams SL, Alley SJ (2020) Depression, Anxiety and Stress during COVID-19: Associations with Changes in Physical Activity, Sleep, Tobacco and Alcohol Use in Australian Adults. International journal of environmental research and public health 17(11): 4065 .

11. Goularte JF, Serafim SD, Colombo R, Hogg B, Caldieraro MA, et al. (2021) COVID-19 and mental health in Brazil: Psychiatric symptoms in the general population. Journal of psychiatric research 132: 32-37.

\section{ISSN: 2574-1241}

DOI: 10.26717/BJSTR.2021.34.005624

Ednaldo Dos Santos. Biomed J Sci \& Tech Res

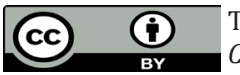

This work is licensed under Creative Commons Attribution 4.0 License

Submission Link: https://biomedres.us/submit-manuscript.php

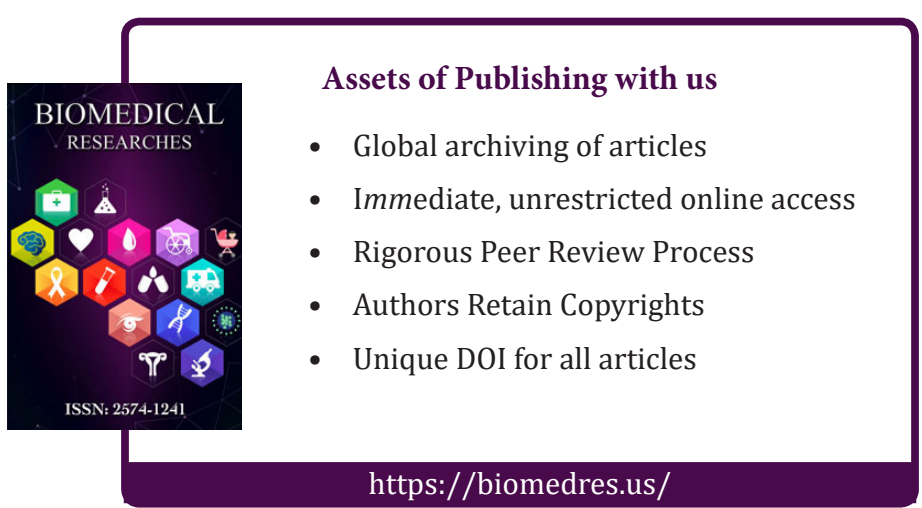

